\title{
Cost-effectiveness analysis of dabigatran, rivaroxaban and warfarin in the prevention of stroke in patients with atrial fibrillation in China
}

\author{
Hongtao Wei, Can Cui, Xiangli Cui , Yi Liu and Dandan Li
}

\begin{abstract}
Background and objective: To evaluate the cost-effectiveness of new anticoagulants and warfarin in the prevention of stroke in Chinese patients with atrial fibrillation (AF).

Methods: The Markov model was constructed to compare patients' quality-adjusted life-years (QALYs) using drug cost, the cost of the examination after taking a drug, and the incremental cost of other treatments. Both dabigatran (110 and $150 \mathrm{mg}$, twice a day) and rivaroxaban (20 mg, once a day) were compared with warfarin (3-6 mg, once a day). Willingness to pay, three times the 2018 China GDP per capita (9481.88 \$), was the cost-effect threshold in our study.

Results: The total cost were was 5317.31\$, 29673.33\$, 23615.49\$, and 34324.91\$ for warfarin, rivaroxaban, dabigatran $110 \mathrm{mg}$ bid, and dabigatran $150 \mathrm{mg}$ bid, respectively. The QALYs for each of the four interventions were 11.07 years, 15.46 years, 12.4 years, and 15 years, respectively. The cost-effectiveness analysis of the three new oral anticoagulants and warfarin showed that the incremental cost-effectiveness ratio (ICER) was 5548.07\$/QALY when rivaroxaban was compared with warfarin. Rivaroxaban was the most cost-effective choice and warfarin was the least.

Conclusions: In Chinese patients with AF, although warfarin is cheaper, rivaroxaban has a better cost-effectiveness advantage from an economic point of view.
\end{abstract}

Keywords: Warfarin, Cost-effectiveness, New oral anticoagulants, Chinese population

\section{Background}

Atrial fibrillation (AF) is one of the most common cardiac arrhythmias, Which could increase the incidence of diseases such as acute ischemic stroke, heart failure, and myocardial infarction [1]. The prevalence of AF in China is 0.61 to $0.77 \%$ [2], which was $0.3-0.48 \%$ higher than the average international rate $[3,4]$. The total incidence of AF was $1.46 \%$ in southern China during 2017-2018

\footnotetext{
*Correspondence: cui10@163.com

Department of Pharmacy, Beijing Friendship Hospital, Capital Medical University, 100050 Beijing, China
}

$[5,6]$. The incidence increased with age, reaching $5 \%$ in patients aged 80 years or older [7]. Around $20-30 \%$ of ischemic stroke was caused by AF [8], which might likely lead to disability and significantly reduce the quality of life for patients [9-11] and increase the burden of chronic care $[12,13]$. Therefore, effectively to prevent AF-induced cardiogenic embolism is particularly essential.

In the past, warfarin was the most effective method to prevent stroke caused by AF. However, the use of warfarin is complicated, and it needs to be closely

(c) The Author(s). 2021 Open Access This article is licensed under a Creative Commons Attribution 4.0 International License, which permits use, sharing, adaptation, distribution and reproduction in any medium or format, as long as you give appropriate credit to the original author(s) and the source, provide a link to the Creative Commons licence, and indicate if changes were made. The images or other third party material in this article are included in the article's Creative Commons licence, unless indicated otherwise in a credit line to the material. If material is not included in the article's Creative Commons licence and your intended use is not permitted by statutory regulation or exceeds the permitted use, you will need to obtain permission directly from the copyright holder. To view a copy of this licence, visit http://creativecommons.org/licenses/by/4.0/ The Creative Commons Public Domain Dedication waiver (http://creativecommons.org/publicdomain/zero/1.0/) applies to the data made available in this article, unless otherwise stated in a credit line to the data. 
monitored with INR values. Moreover, some studies have shown that the preventive effect of warfarin is significantly lower in Asians than Caucasians, and bleeding events are more likely to occur in Asians [14, 15]. In recent years, novel oral anticoagulants (NOACs), which have better safety, efficacy, and compliance properties, provide a new choice for AF patients [16, 17]. However, the NOACs are more expensive. This article aimed to evaluate whether NOACs, dabigatran, and rivaroxaban, have a cost-effectiveness advantage compared with warfarin for stroke prevention among AF patients in China through pharmacoeconomics analysis.

\section{Methods}

\section{Evaluation method}

This study started with the payer and used a costeffectiveness analysis to construct a Markov model. The model was used to compare the cost and effectiveness of warfarin, rivaroxaban, and dabigatran $(110 \mathrm{mg}$ and $150 \mathrm{mg}$ ) in the prevention of stroke and myocardium infarction in patients with non-valvular AF (NVAF).

\section{Model specification}

An individual-level simulation model was built to predict the clinical events and outcomes of each patient over time under different treatment regimens. According to the natural history of disease development, the survival status of patients with NVAF was divided into four conditions: mild (no event of AF or no sequelae of events), moderate (moderate disability survival), severe (need help to survive) and death. Clinical manifestations in the model simulation were ischemic stroke (IS), intracranial hemorrhage $(\mathrm{ICH})$, extracranial hemorrhage $(\mathrm{ECH})$, myocardial infarction (MI) and death. At the beginning of the cycle, all patients were of mild status. With the cycle running, clinical events occurred, and individuals switched between states. The flow chart of the model is shown in Fig. 1. The model cycle was one year, and the study period was 30 years with a discount rate of $3 \%$. Willingness to pay, three times the 2018 China GDP per capita (9481.88 \$), was the cost-effect threshold in our study .

\section{Model Assumptions}

We assumed the following hypothesis: (1) patients can experience any but only one clinical event in each cycle, (2) the conversion rate of each event in the model does not change with time, (3) assuming extracranial hemorrhage and MI have only two outcomes, namely patients with mild illness or death, (4) severely ill status is a state of irrecoverable disability and entirely in need of survival. It is assumed that once an individual enters the state of a severely ill condition, there are only two outcomes: maintenance and death, and (5) ignoring the occurrence of clinical events may lead to changes in costs due to drug withdrawals and others.

\section{Sensitivity Analysis}

One-way sensitivity analyses were performed using Tree Age Pro 2011 software to test the robustness of the model results. Plausible ranges were obtained from the literature. To evaluate the impact of the uncertainty in all variables simultaneously, a probabilistic sensitivity analysis was performed using the Monte Carlo simulation. Probabilistic sensitivity analyses were performed through the second-order Monte Carlo simulation model

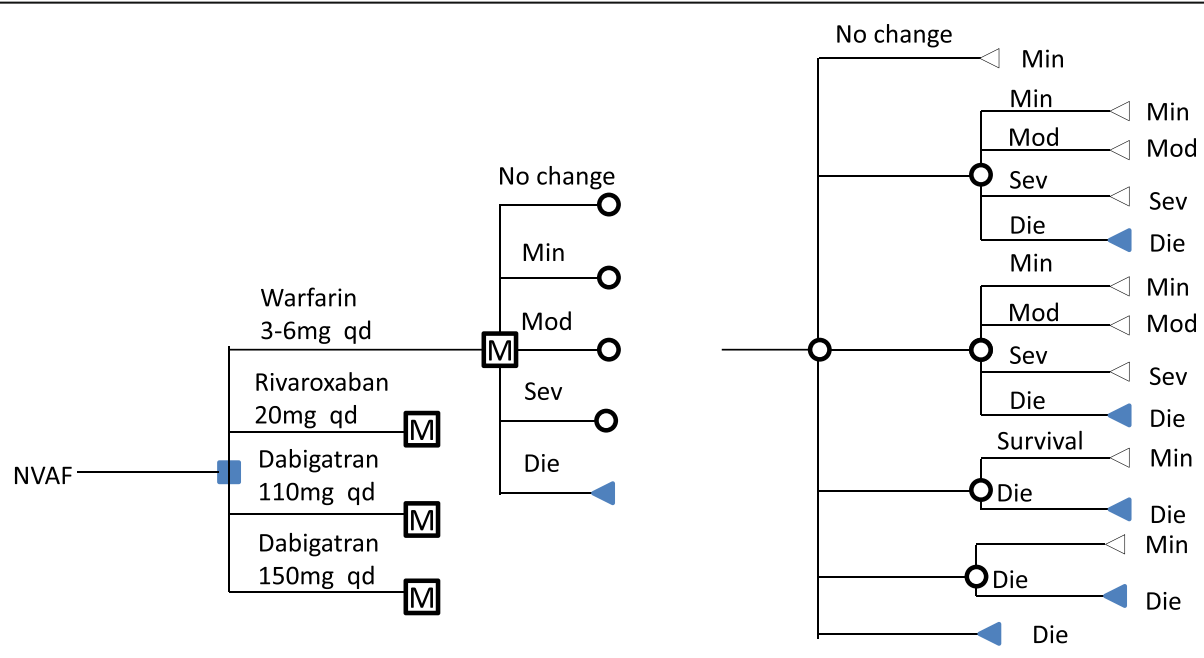

Fig. 1 Representation of the Markov model. The four treatment options are shown on the left. "M"represents a Markov process with 4 health states. These health states are identical for each treatment option. "Min" represent state without incident or sequelae, "Mod" represent moderate disabilities, "Sev" represent completely disabilities, Die means death. All patients remain in the "Min"state until one of the five events occurs. NVAF, nonvalvular atrial fibrillation; IS, ischemic stroke; ICH, intracranial hemorrhage; ECH, extracranial hemorrhage; MI, myocardial infarction 
(1,000 times). Costs varied after assuming a log- normal distribution. Probabilities and utilities varied according to a beta distribution. Uncertainty was represented on a scatterplot and cost-effectiveness acceptability curve.

\section{Data sources}

\section{Therapeutic effect and conversion rate}

Transition probability refers to the probability that a patient moves from one state to various states in one cycle. To obtain the closest conversion rate of the Chinese population, Re-ly15, XANTUS16, ROCKET AF17 trials, and relevant literature were considered18-20. All included subjects were Chinese or subgroup analysis of the Asian population. The Re-ly trial selected 541 AF patients from the Chinese subgroup, which was a randomized efficacy comparison warfarin and dabigatran (110 mg or $150 \mathrm{mg}$, twice daily) in long-term anticoagulant therapy. The XANTUS trial included 2,273 Chinese (including Hong Kong and Taiwan), which was a prospective real-world observation study, comparing different doses of rivaroxaban in NVAF patients. Results are shown in Table 1.

\section{Cost}

The state of NVAF event-free costs were the average annual direct medical costs of the four treatment measures, including medical service costs, medication costs, and related examination costs. The medical service charge was 50 yuan per time for general outpatient service in the tertiary hospital of Beijing. The drug cost referred to the public price from the Beijing Sunshine Drug Procurement platform. The coagulation function monitoring cost was 3.73 \$/test. Warfarin's coagulation function monitoring frequency was based on the 2015 guidelines for stroke prevention and treatment in patients with AF in China23. INR is monitored 21 times a year, and the monitoring frequency for NOACs is once a year. The average hospital expenses for acute events were obtained from the 2018 China Health Statistics Yearbook, as shown in Table 1.

The dose of warfarin was adjusted based on INR, and the daily dose fluctuated between 1.5 and $-6 \mathrm{mg}$, resulting in a change in drug costs. The recommended dosage of rivaroxaban for an adult with NVAF was between 15 and $20 \mathrm{mg} / \mathrm{d}$. There are three dosage strengths of $10 \mathrm{mg}$, $15 \mathrm{mg}$, and $20 \mathrm{mg}$ for rivaroxaban, and the cost of $20 \mathrm{mg} /$ day of rivaroxaban was used in our analysis. The dosage of dabigatran was adjusted from $110 \mathrm{mg}$ or $150 \mathrm{mg}$, twice daily, according to the risk of bleeding, as shown in Table 1.

\section{Value of health utility}

The quality-adjusted life year (QALY) was adopted as the health utility index in this analysis. The value of health utility was derived from a similar population investigation and published literature. Assuming that QALY is 1 for health and 0 for death, EQ-5D was used to calculate the quality of life under specific condition, and the health utility values in each state are shown in Table 1.

\section{Results \\ Basic analysis}

The results showed that the total cost of warfarin, rivaroxaban, dabigatran $(110 \mathrm{mg}$ bid, and $150 \mathrm{mg}$ bid) in NVAF patients was 5317.31 \$, 29673.33 \$, 23615.48 \$, and 34324.91 \$, respectively. The available QALY value was $11.07,15.46,12.4$, and 15 years, respectively. The efficiency of dabigatran $150 \mathrm{mg}$ was the lowest due to its high cost. According to the recommendation of the World Health Organization on pharmaceutical economics evaluation, we took three times of the 2018 China GDP as the cost-effect threshold in our study. The result of an incremental cost-effectiveness ratio (ICER) showed that rivaroxaban was 5548.07 \$/QALY, which was the best therapeutic regimen. The results are shown in Table 2.

2.2 Sensitivity Analysis.

Tornado analysis showed that PwarST (probability of ischemic stroke in warfarin), PwarICH (probability of hemorrhagic stroke in warfarin), Umin (health utility value of mild patients), and Criv (rivaroxaban price) were the most influential variables of this model, as shown in Fig. 2.

A sensitivity analysis was carried out to assess these four significant, influential factors. The results showed that when the probability of ischemic stroke and hemorrhagic stroke in warfarin was adjusted to the minimum, the ICER of rivaroxaban compared to warfarin was 8176.64 and 6189.53 \$, respectively. When ICER is less than one time the GDP, rivaroxaban had absolute economic advantages. When the annual quality of life Umin in the mildly diseased state was adjusted to a maximum value of 0.9 and a minimum value of 0.7 , the ICER of rivaroxaban over warfarin was 4645.53 \$ and 6058.70 \$, respectively. Rivaroxaban still had absolute economic advantages. When the price of rivaroxaban was adjusted to the maximum value, the ICER was 9281.07 \$, and rivaroxaban still maintained an absolute economic benefit, which was consistent with the baseline analysis, as shown in Table 3.

\section{Probabilistic sensitivity analyses}

The cost-effectiveness acceptable curve was obtained (Fig. 3). When the WTP was greater than 7587.27 \$, the acceptable probability of rivaroxaban was close to $100 \%$, and dabigatran was always in a disadvantaged scenario. 
Table 1 Base-case model variables and ranges used in a sensitivity analysis

\begin{tabular}{|c|c|c|c|}
\hline Variable & Value & Range & Reference \\
\hline \multicolumn{4}{|l|}{ Probabilities } \\
\hline \multicolumn{4}{|c|}{ Probability of ischemic stroke caused by different drugs } \\
\hline Warfarin & 0.04 & $0.023-0.0453$ & [18-20] \\
\hline Rivaroxaban & 0.0193 & NA & [19] \\
\hline Dabigatran110mg & 0.0183 & $0.0167-0.0189$ & {$[18,19]$} \\
\hline Dabigatran150mg & 0.0137 & NA & [20] \\
\hline \multicolumn{4}{|c|}{ Probability of ischemic stroke outcome by severity } \\
\hline Light & 0.091 & $0.091-0.133$ & [21] \\
\hline Moderate & 0.425 & $0.348-0.425$ & [21] \\
\hline Severe & 0.402 & $0.402-0.417$ & [21] \\
\hline Die(in 30day) & 0.082 & $0.082-0.101$ & [21] \\
\hline \multicolumn{4}{|c|}{ Probability of $\mathrm{ICH}$ caused by different drugs } \\
\hline Warfarin & 0.0121 & $0.0057-0.0294$ & {$[18,19,22]$} \\
\hline Rivaroxaban & 0.00257 & $0.0021-0.0033$ & {$[19,22]$} \\
\hline Dabigatran110mg & 0.00359 & $0.0028-0.0039$ & {$[18,19]$} \\
\hline Dabigatran150mg & 0.0027 & NA & [18] \\
\hline \multicolumn{4}{|c|}{ Probability of ICH outcome by severity } \\
\hline Light & 0.12 & NA & {$[21,23]$} \\
\hline Moderate & 0.27 & NA & {$[21,23]$} \\
\hline Severe & 0.43 & NA & {$[21,23]$} \\
\hline Die & 0.18 & NA & {$[21,23]$} \\
\hline \multicolumn{4}{|c|}{ Probability of ECH caused by different drugs } \\
\hline Warfarin & 0.027 & NA & [24] \\
\hline Rivaroxaban & 0.03 & NA & [23] \\
\hline Dabigatran110mg & 0.007 & NA & [24] \\
\hline Dabigatran150mg & 0.0217 & NA & [23] \\
\hline \multicolumn{4}{|c|}{ Probability of ECH outcome by severity } \\
\hline Die & 0.0147 & $0.01-0.04$ & [21] \\
\hline \multicolumn{4}{|c|}{ Probability of Ml caused by different drugs } \\
\hline Warfarin & 0.0098 & NA & [21] \\
\hline Rivaroxaban & 0.0098 & NA & [21] \\
\hline Dabigatran110mg & 0.0072 & NA & [18] \\
\hline Dabigatran150mg & 0.0074 & NA & [18] \\
\hline \multicolumn{4}{|c|}{ Probability of Ml outcome by severity } \\
\hline Death & 0.166 & $0.158-0.174$ & {$[21,25]$} \\
\hline \multicolumn{4}{|c|}{ All-cause mortality by different drugs } \\
\hline Warfarin & 0.026 & $0.0258-0.0261$ & {$[18,22]$} \\
\hline Rivaroxaban & 0.0164 & NA & [22] \\
\hline Dabigatran110mg & 0.0333 & NA & [18] \\
\hline Dabigatran150mg & 0.0219 & NA & [18] \\
\hline \multicolumn{4}{|l|}{ Cost } \\
\hline Price (specification/\$) & & Range of daily dose & \\
\hline warfarin & 3 mg/0.07 & $1.5 \mathrm{mg}-6 \mathrm{mg} / \mathrm{d}$ & \\
\hline Rivaroxaban & $20 \mathrm{mg} / 4.87$ & $15-20 \mathrm{mg}$ qd & \\
\hline
\end{tabular}


Table 1 Base-case model variables and ranges used in a sensitivity analysis (Continued)

\begin{tabular}{|c|c|c|c|}
\hline Variable & Value & Range & Reference \\
\hline Dabigatran110mg & $110 \mathrm{mg} / 2.34$ & $110-150 \mathrm{mg}$ bid & \\
\hline Dabigatran150mg & $150 \mathrm{mg} / 3.01$ & $110-150 \mathrm{mg}$ bid & \\
\hline Cost of examination and service & 10.77 & NA & \\
\hline \multicolumn{4}{|c|}{ Frequency about examination/Annual } \\
\hline warfarin & 21 & NA & [26] \\
\hline Rivaroxaban and Dabigatran & 1 & NA & \\
\hline \multicolumn{4}{|l|}{ Total cost \$(drug and examination) } \\
\hline Warfarin & 253.30 & $239.70-280.51$ & \\
\hline Rivaroxaban & 1787.00 & $1435.86-2844.52$ & \\
\hline Dabigatran110mg & 1718.21 & $1711.17-2206.93$ & \\
\hline Dabigatran150mg & 2206.93 & $1711.17-2206.93$ & \\
\hline \multicolumn{4}{|l|}{ Event } \\
\hline Stroke & 1351.20 & $851.36-2681.69$ & \\
\hline $\mathrm{ICH}$ & 2605.43 & 1935.86-3862.05 & \\
\hline $\mathrm{ECH}$ & 1216.72 & $867.23-2516.68$ & \\
\hline Ml & 3875.18 & 1805.02-5529.89 & \\
\hline \multicolumn{4}{|l|}{ Health utility values in each state } \\
\hline Light & 0.76 & $0.7-0.9$ & [27] \\
\hline Moderate & 0.39 & $0.1-0.5$ & [27] \\
\hline Severe & 0.16 & $0.0-0.32$ & [27] \\
\hline $\mathrm{ICH}$ & 0.8 & $0.79-0.84$ & [28] \\
\hline $\mathrm{ECH}$ & 0.8 & $0.79-0.84$ & [28] \\
\hline Ml & 0.84 & $0.67-0.96$ & [29] \\
\hline
\end{tabular}

ICH Intracranial hemorrhage; ECH Extracranial hemorrhage; MI Myocardial infarction

The ICER scatter plot (Fig. 4) reflects the change and concentration of the ICER value in the probabilistic sensitivity analysis. When the WTP was three times the GDP 28445.64 \$, most values fell within the confidence interv al. Rivaroxaban was more cost-effective than other options.

\section{Discussion}

In this study, previously published population data of patients with AF in China receiving different oral anticoagulant treatments were included in the Markov model for cost-effectiveness analysis. The weighted average method was utilized in our research. Transition probability data came from randomized controlled trials and the utility values date were from cohort studies or population-based studies. In the real world, many factors [30-32], such as low patient compliance and medication errors, might have influenced disease [33, 34]. Thus, it might be difficult to estimate these factors. Therefore they were not calculated or discussed in our research.

As a common chronic disease, the Markov model is used to simulate the disease's progression and control, which has certain significance in guiding the long-term clinical use of medications. It has been reported that the age of patients with atrial fibrillation is between 20 and 99 years old [35]. The survival time of patients with atrial fibrillation can be several decades. Therefore we choose a more extended period of 30 years for the cycle simulation.

Table 2 cost-effectiveness comparison

\begin{tabular}{llllll}
\hline & Utility(QALY) & Increased utility & Cost(\$) & Increased costs & ICER \\
\hline warfarin & 11.07 & & 5317.31 & & \\
Rivaroxaban & 15.46 & 4.39 & 29673.33 & 24356.02 & 5548.07 \\
Dabigatran110mg & 12.40 & 1.33 & 23615.48 & 18298.17 & 13758.02 \\
Dabigatran150mg & 15.00 & 3.93 & 34324.91 & 29007.60 & 7381.07 \\
\hline
\end{tabular}




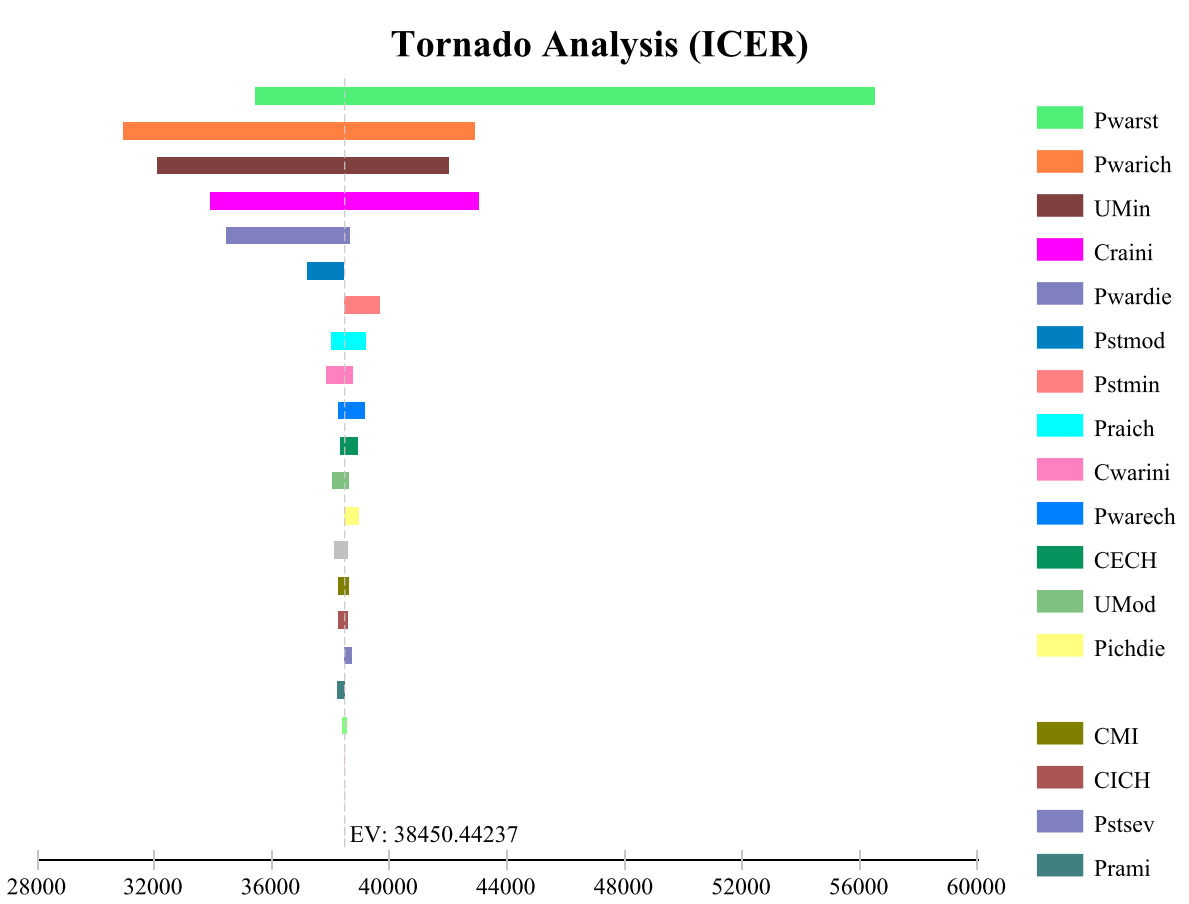

Fig. 2 Tornado analysis (ICER). Cost per additional quality-adjusted life year (bars) of rivaroxaban compared to adjusted-dose warfarin as determined in tornado diagram over plausible ranges for all variables. The willingness-to-pay threshold of 202295.67 yuan per quality-adjusted life year are presented.

The cost data of this study includes three aspects: the cost of the drug, the examination fees when taking the drug, and the cost of the treatment after disease occurrence. The cost of drug treatment is based on fixed drug pricing from the Beijing drug procurement platform. The examination fees are the fees set by the medical institution. Both of these two types of fees are statecontrolled prices. The cost of treating AF-induced stroke or MI is the average cost listed in the 2018 Chinese Health Yearbook. From the cost of drug treatment alone, the average daily cost of warfarin is $0.04-0.15$ \$, which is much lower than 4.68 \$ for dabigatran $110 \mathrm{mg}, 6.02$ \$

Table 3 one-way sensitivity analysis results

\begin{tabular}{ll}
\hline ICER(Cost/QALY) & one-way sensitivity analysis \\
\hline Basic analysis & 5548.07 \\
PwarST Adjust to maximum & 5112.44 \\
PwarST Adjust to minimum & 8176.64 \\
PwarlCH Adjust to maximum & 4470.03 \\
PwarlCH Adjust to minimum & 6189.53 \\
Umin Adjust to maximum & 4645.53 \\
Umin Adjust to minimum & 6058.70 \\
Cost of rivaroxaban Adjust to maximum & 9281.03 \\
Cost of rivaroxaban Adjust to minimum & 4311.95 \\
\hline
\end{tabular}

ICER incremental cost-effectiveness ration; PwarST Risk of cerebral infarction with warfarin; PwarlCH Risk of intracranial hemorrhage with warfarin; Umin Quality of life adjusted years in patients with mild dysfunction for dabigatran $150 \mathrm{mg}$, and 4.87 \& for rivaroxaban. However, warfarin needs to monitor the INR regularly for a long time, and each monitoring visit requires consultation and examination fees. After adding these fees, the average treatment cost of warfarin is only 0.39 \$, still far lower than dabigatran and rivaroxaban.

The results of this study show that the use of warfarin QALYs is 11.07, and the cost of drug treatment, examination, and disease treatment for 30 years is 5317.31\$. Since warfarin has a higher risk of stroke, the cost of treating cardiogenic embolism and subsequent rehabilitation is higher [36, 37], therefore, more effective treatments should be selected. Compared with warfarin, for each additional QALY, the costs are rivaroxaban 5550.18 \$, dabigatran (150 mg) 13772.09 \$, and dabigatran (110 mg) 7381.07\$. In 2017, the per capita GDP of China was 9481.88 \$ [38]. We take three times the GDP as WTP for further analysis. Rivaroxaban has the highest cost-effectiveness, followed by warfarin. Dabigatran $150 \mathrm{mg}$ and $110 \mathrm{mg}$ have poor cost-effectiveness. Among them, dabigatran $150 \mathrm{mg}$ has an extended advantage, and dabigatran $110 \mathrm{mg}$ has an absolute disadvantage. When WTP is lower than 53945.51 yuan, warfarin has the highest cost-effectiveness, which is similar to previous studies in Taiwan [39], South Korea [40], and Hong Kong [19].

Previous foreign studies have shown that all NOACs have cost-effectiveness advantages compared to warfarin. 


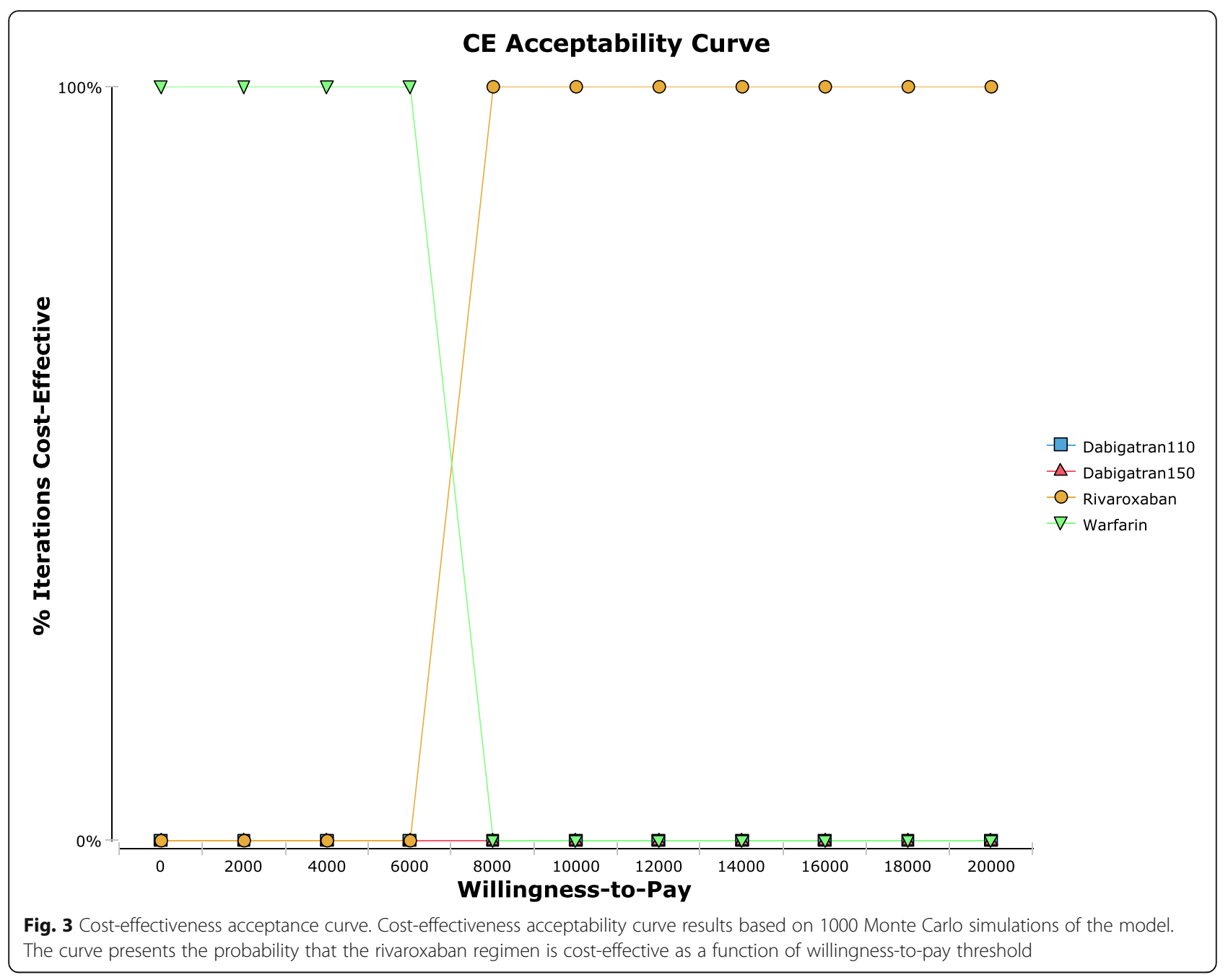

Among them, apixaban has the best cost-effectiveness in preventing stroke in patients with atrial fibrillation. However, because of the latest approval of apixaban in mainland China and limited clinical use, apixaban was not included in the analysis. Rivaroxaban and dabigatran are sold at different prices in different regions, leading to changes in cost-effect results. If the price of rivaroxaban is reduced by $30 \%$, rivaroxaban has a better cost effect. At a willingness-to-pay threshold of $£ 20,000$ per qualityadjusted life-year (QALY), all NOACs had the positive expected incremental net benefit (INB) compared with warfarin.

In this study, a single-factor sensitivity analysis was performed using Tree Age Pro 2011 software. With the WTP value of 8452.27 \$, tornado plot analysis shows that PwarST (probability of ischemic stroke in warfarin), PwarICH (probability of hemorrhagic stroke in warfarin), Umin (year of quality of life in mildly diseased condition), and Criv (rivaroxaban price) are the most influential parameters for the model. The probability of ischemic stroke with warfarin is the most influential factor in the model.In previous studies, the effective control rate of INR was also an important influencing factor when taking warfarin [41]. When time in therapeutic range $\geq 65 \%$, the risk of ischemic stroke was reduced by warfarin [19]. However, whether warfarin therapy is well-managed or not,rivaroxaban still has absolute economic benefits. The probability of ischemic stroke in warfarin adjusted from minimum to maximum, the ICER of rivaroxaban is adjusted from 6189.53 \$ to $9281.03 \$$, which is consistent with the analysis of baseline results.

\section{Limitations}

Furthermore, several limitations are worthy of discussion in this study. First, our research mainly focuses on the results of the Chinese population, but the number of Chinese population included in these randomized controlled studies is limited. Researches published in China are also non-systematic, therefore the included data is limited, leading to deviations in the results. Especially the conversion rate of different disease states, which is 


\section{Incremental Cost-Effectiveness, Rivaroxaban v. Warfarin}

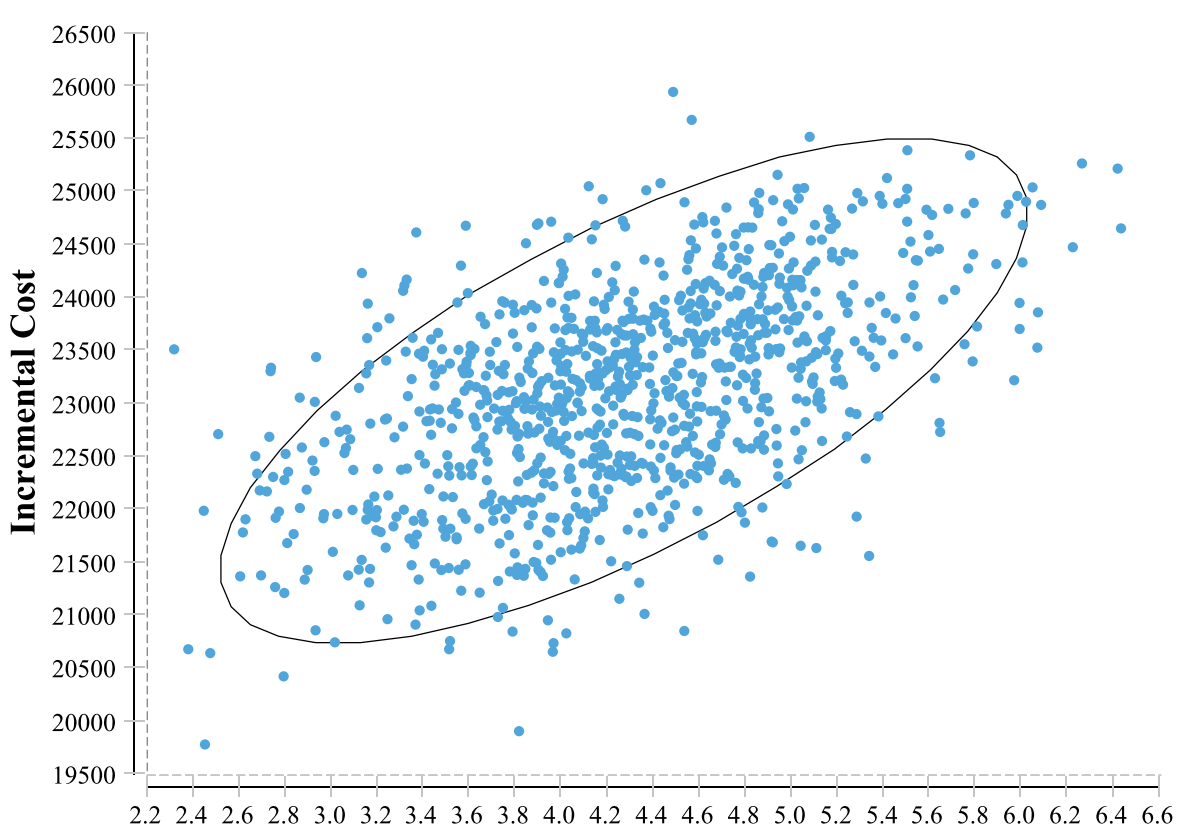

Incremental Effectiveness

Fig. 4 Incremental Cost-Effectiveness Rate scatter. Incremental cost-effectiveness scatterplot of the result of the probabilistic sensitivity analysis. Each point represents a simulation. Ellipse represents $95 \%$ confidence interval ellipse

most likely to be affected. Second, in China, the out-ofpocket expenses in the medical process vary significantly among different groups of people. Some people pay the full amount at their own expense, some only pay a small part (paid by medical insurance), and some do not need to pay at all. This social phenomenon may lead to large differences in the choice of therapeutic drugs among different groups of people. Third, although we have included the cost of patients' medical treatment, examinations, and medicines into the cost part, the cost of caring for patients, and salary loss were not included. Therefore, the disease may underestimate the quality of life of patients.

\section{Conclusions}

In the Chinese population, oral anticoagulants are used to prevent AF-related cardiac embolism. Although warfarin treatment is less expensive, rivaroxaban is a better cost-effectiveness choice.

\section{Abbreviations}

AF: Atrial fibrillation; QALYs: quality-adjusted life-years; ICER: incremental costeffectiveness ratio; NOACs: Novel oral anticoagulants; NVAF: Non-valvular atrial fibrillation; IS: Ischemic stroke; ICH: Intracranial hemorrhage; ECH: Extracranial hemorrhage; MI: Myocardial infarction; Min: Minor; Mod: Moderate; Sev: Severe; Die: Dead; PwarST: Risk of cerebral infarction with warfarin; PwarlCH: Risk of intracranial hemorrhage with warfarin; Umin: Quality of life adjusted years in patients with mild dysfunction; GDP: Gross domestic product

\section{Acknowledgements}

The authors thank Dr. Li Xingang frm Department of Pharmacy, Beijing Friendship Hospital for his valuable help in article translation and language editing.

\section{Authors' contributions}

XL C contributed to the conception of the study;HT W performed the data analyses and wrote the manuscript; C C contributed significantly to analysis and manuscript preparation; $\mathrm{L}$ and $\mathrm{DD} L$ helped perform the analysis with constructive discussion.All authors have read and approved the manuscript.

\section{Funding}

This study received no funding.

Availability of data and materials

The datasets generated and/or analysed during the current study are available upon request.

Ethics approval and consent to participate

We have stated that Ethics approval and consent to participate: No applicable.

Access and use the data/records described in this study,which need no permission.

Consent for publication

Not Applicable.

Competing interests

All author declared no conflicts of interest. 
Received: 25 April 2020 Accepted: 13 January 2021

Published online: 28 January 2021

\section{References}

1. Hindricks G, Potpara T, Dagres N, Arbelo E, Bax JJ, Blomström-Lundqvist C, Boriani G, Castella M, Dan GA, Dilaveris PE, et al: 2020 ESC Guidelines for the diagnosis and management of atrial fibrillation developed in collaboration with the European Association of Cardio-Thoracic Surgery (EACTS). European heart journal 2020

2. Zhou ZQ, Hu DY, Chen J, Zhang RH, Li KB, Zhao XL. [An epidemiological survey of atrial fibrillation in China]. Zhonghua nei ke za zhi. 2004;43(7):491-4

3. Rahman F, Kwan GF, Benjamin EJ. Global epidemiology of atrial fibrillation. Nature reviews Cardiology. 2014;11(11):639-54.

4. Chugh SS, Havmoeller R, Narayanan K, Singh D, Rienstra M, Benjamin EJ, Gillum RF, Kim YH, McAnulty JH Jr, Zheng ZJ, et al. Worldwide epidemiology of atrial fibrillation: a Global Burden of Disease 2010 Study. Circulation. 2014;129(8):837-47.

5. Bjorck S, Palaszewski B, Friberg L, Bergfeldt L. Atrial fibrillation, stroke risk, and warfarin therapy revisited: a population-based study. Stroke. 2013; 44(11):3103-8

6. Haim M, Hoshen M, Reges O, Rabi Y, Balicer R, Leibowitz M. Prospective national study of the prevalence, incidence, management and outcome of a large contemporary cohort of patients with incident non-valvular atria fibrillation. Journal of the American Heart Association. 2015;4(1):e001486.

7. Deng H, Guo P, Zheng M, Huang J, Xue Y, Zhan X, Wang F, Liu Y, Fang $X$, Liao $H$, et al. Epidemiological Characteristics of Atrial Fibrillation in Southern China: Results from the Guangzhou Heart Study. Scientific reports. 2018;8(1):17829.

8. Marini C, De Santis F, Sacco S, Russo T, Olivieri L, Totaro R, Carolei A. Contribution of atrial fibrillation to incidence and outcome of ischemic stroke: results from a population-based study. Stroke. 2005;36(6):1115-9.

9. Wolf PA, Abbott RD, Kannel WB. Atrial fibrillation as an independent risk factor for stroke: the Framingham Study. Stroke. 1991;22(8):983-8.

10. Krahn AD, Manfreda J, Tate RB, Mathewson FA, Cuddy TE. The natural history of atrial fibrillation: incidence, risk factors, and prognosis in the Manitoba Follow-Up Study. Am J Med. 1995;98(5):476-84.

11. Stewart S, Hart CL, Hole DJ, McMurray JJ. A population-based study of the long-term risks associated with atrial fibrillation: 20-year follow-up of the Renfrew/Paisley study. Am J Med. 2002;113(5):359-64.

12. Charfi N, Trabelsi S, Turki M, Maalej Bouali M, Zouari L, Dammak M, Ben Thabet J, Mhiri C, Maalej M. [Impact of physical disability and concomitant emotional disturbances on post-stroke quality of life]. L'Encephale. 2017; 43(5):429-34.

13. Yan LL, Chen S, Zhou B, Zhang J, Xie B, Luo R, Wang N, Lindley R, Zhang $Y$, Zhao $Y$, et al. A randomized controlled trial on rehabilitation through caregiver-delivered nurse-organized service programs for disabled stroke patients in rural china (the RECOVER trial): design and rationale. International journal of stroke: official journal of the International Stroke Society. 2016;11(7):823-30.

14. Chiang CE, Wang KL, Lip GY. Stroke prevention in atrial fibrillation: an Asian perspective. Thromb Haemost. 2014;111(5):789-97.

15. Vivas D, Olmos C, Vilacosta I. Atrial fibrillation and anticoagulation therapy: different race, different risk, and different management? Circulation journal: official journal of the Japanese Circulation Society. 2011;75(6):1314-5.

16. Gallego P, Roldan V, Lip GY. Conventional and new oral anticoagulants in the treatment of chest disease and its complications. Am J Respir Crit Care Med. 2013;188(4):413-21.

17. Ghanny S, Crowther M. Treatment with novel oral anticoagulants: indications, efficacy and risks. Curr Opin Hematol. 2013;20(5):430-6.

18. Xin G, Yanmin Y, Jun Z, Yan D, Huiqiong T. Dabigatran versus warfarin for the prevention of stroke in Chinese patients with nonvalvular atrial fibrillation:Chinese subpopulation analysis of RE-LY. Chinese Journal of Cardiology. 2016;44(11):929-34.

19. Li WH, Huang D, Chiang CE, Lau CP, Tse HF, Chan EW, Wong ICK, Lip GYH, Chan $\mathrm{PH}$, Siu CW. Efficacy and safety of dabigatran, rivaroxaban, and warfarin for stroke prevention in Chinese patients with atrial fibrillation: the Hong Kong Atrial Fibrillation Project. Clinical cardiology. 2017;40(4):222-9.

20. Wu S, Xie S, Xu Y, Que D, Yau TO, Wang L, Huang Y. Persistence and outcomes of non-vitamin $\mathrm{K}$ antagonist oral anticoagulants versus warfarin in patients with non-valvular atrial fibrillation. Journal of clinical nursing. 2019; 28(9-10):1839-46.

21. Kim H, Kim H, Cho SK, Kim JB, Joung B, Kim C. Cost-Effectiveness of Rivaroxaban Compared to Warfarin for Stroke Prevention in Atrial Fibrillation. Korean Circ J. 2019;49(3):252-63.

22. Sun Y, Hu D, Stevens S, Lokhnygina Y, Becker RC, Berkowitz SD, Breithardt G, Hacke W, Halperin JL, Hankey GJ, et al. Efficacy and safety of rivaroxaban versus warfarin in patients from mainland China with nonvalvular atrial fibrillation: A subgroup analysis from the ROCKET AF trial. Thrombosis research. 2017;156:184-90.

23. Kim YH, Shim J, Tsai CT, Wang CC, Vilela G, Muengtaweepongsa S, Kurniawan M, Maskon O, Li Fern H, Nguyen TH, et al. XANAP: A real-world, prospective, observational study of patients treated with rivaroxaban for stroke prevention in atrial fibrillation in Asia. Journal of arrhythmia. 2018, 34(4):418-27.

24. Lau WCY, Douglas IJ, Wong ICK, Smeeth L, Lip GYH, Leung WK, Siu CW, Cheung BMY, Mok MTC, Chan EW. Thromboembolic, bleeding, and mortality risks among patients with nonvalvular atrial fibrillation treated with dual antiplatelet therapy versus oral anticoagulants: A populationbased study. Heart Rhythm 2019.

25. Krumholz HM, Merrill AR, Schone EM, Schreiner GC, Chen J, Bradley EH, Wang Y, Wang Y, Lin Z, Straube BM, et al. Patterns of hospital performance in acute myocardial infarction and heart failure 30-day mortality and readmission. Circulation Cardiovascular quality outcomes. 2009;2(5):407-13.

26. Commission NHaFP. Guidelines for the prevention and treatment of stroke in patients with atrial fibrillation in China; 2015.

27. Gage BF, Cardinalli AB, Owens DK. The effect of stroke and stroke prophylaxis with aspirin or warfarin on quality of life. Arch Intern Med. 1996; 156(16):1829-36

28. Tung CE, Win SS, Lansberg MG. Cost-effectiveness of tissue-type plasminogen activator in the 3- to 4.5-hour time window for acute ischemic stroke. Stroke. 2011:42(8):2257-62.

29. Sullivan PW, Ghushchyan V. Preference-Based EQ-5D index scores for chronic conditions in the United States. Medical decision making: an international journal of the Society for Medical Decision Making. 2006; 26(4):410-20.

30. Lip GY, Nieuwlaat R, Pisters R, Lane DA, Crijns HJ. Refining clinical risk stratification for predicting stroke and thromboembolism in atrial fibrillation using a novel risk factor-based approach: the euro heart survey on atria fibrillation. Chest. 2010;137(2):263-72

31. Ntaios G, Papavasileiou V, Makaritsis K, Vemmos K, Michel P, Lip GYH. RealWorld Setting Comparison of Nonvitamin-K Antagonist Oral Anticoagulants Versus Vitamin-K Antagonists for Stroke Prevention in Atrial Fibrillation: A Systematic Review and Meta-Analysis. Stroke. 2017;48(9):2494-503.

32. Yamashita $Y$, Uozumi R, Hamatani $Y$, Esato M, Chun YH, Tsuji H, Wada H, Hasegawa K, Ogawa H, Abe M, et al. Current Status and Outcomes of Direct Oral Anticoagulant Use in Real-World Atrial Fibrillation Patients- Fushimi AF Registry. Circulation journal: official journal of the Japanese Circulation Society. 2017:81(9):1278-85.

33. Proietti M, Romanazzi I, Romiti GF, Farcomeni A, Lip GYH. Real-World Use of Apixaban for Stroke Prevention in Atrial Fibrillation: A Systematic Review and Meta-Analysis. Stroke. 2018;49(1):98-106.

34. Ha AC, Wijeysundera HC, Birnie DH, Verma A. Real-world outcomes, complications, and cost of catheter-based ablation for atrial fibrillation: an update. Curr Opin Cardiol. 2017;32(1):47-52.

35. Zulkifly H, Lip GYH, Lane DA. Epidemiology of atrial fibrillation. Int J Clin Pract. 2018;72(3):e13070

36. Zhang C, Gu ZC, Ding Z, Shen L, Pan MM, Zheng YL, Lin HW, Pu J. Decreased risk of renal impairment in atrial fibrillation patients receiving non-vitamin K antagonist oral anticoagulants: A pooled analysis of randomized controlled trials and real-world studies. Thrombosis research. 2019;174:16-23.

37. Lopez-Lopez JA, Sterne JAC, Thom HHZ, Higgins JPT, Hingorani AD, Okoli GN, Davies PA, Bodalia PN, Bryden PA, Welton NJ, et al. Oral anticoagulants for prevention of stroke in atrial fibrillation: systematic review, network meta-analysis, and cost effectiveness analysis. Bmj. 2017;359:j5058.

38. Xuegao Z: China Health Statistics Yearbook.China Union Medical University Press; 2018.

39. Liu CY, Chen HC. Cost-Effectiveness Analysis of Apixaban, Dabigatran, Rivaroxaban, and Warfarin for Stroke Prevention in Atrial Fibrillation in Taiwan. Clinical drug investigation. 2017;37(3):285-93. 
40. Kim H, Kim H, Cho S-K, Kim J-B, Joung B, Kim C. Cost-Effectiveness of Rivaroxaban Compared to Warfarin for Stroke Prevention in Atrial Fibrillation. Korean Circulation Journal. 2019;49(3):252.

41. Kirchhof P, Benussi S, Kotecha D, Ahlsson A, Atar D, Casadei B, Castella M, Diener HC, Heidbuchel H, Hendriks J, et al: 2016 ESC Guidelines for the management of atrial fibrillation developed in collaboration with EACTS. Europace: European pacing, arrhythmias, and cardiac electrophysiology : journal of the working groups on cardiac pacing, arrhythmias, and cardiac cellular electrophysiology of the European Society of Cardiology 2016, 18(11):1609-1678.

\section{Publisher's Note}

Springer Nature remains neutral with regard to jurisdictional claims in published maps and institutional affiliations.

Ready to submit your research? Choose BMC and benefit from:

- fast, convenient online submission

- thorough peer review by experienced researchers in your field

- rapid publication on acceptance

- support for research data, including large and complex data types

- gold Open Access which fosters wider collaboration and increased citations

- maximum visibility for your research: over $100 \mathrm{M}$ website views per year

At $\mathrm{BMC}$, research is always in progress.

Learn more biomedcentral.com/submissions 